\title{
Human Figure Drawing (HFD) Test is affected by Cognitive Style
}

\section{Ariela Gigi*}

Department of Psychology \& Behavioral Sciences, Ariel University, Israel

\begin{abstract}
The drawing figures are widely managed as an ideal instrument for self-expression. HFD test (Human Figure Drawing) is an abbreviated test which was developed with the aim to evaluate various psychological states, especially assessing the psychic status including psychiatric illness and personality state. Thus, the reliance on the drawings must be proven that it has no bias due to cognitive differences between subjects. In the present study it is demonstrated that drawing tests are influenced, to a certain extent, by the subject's cognitive style. Although the study was limited here, the results indicate the need for re-examination of the reliability limits of the Test.
\end{abstract}

Keywords: Human figure drawing; Cognitive style; Projective test; Psychodiagnostic

\section{Introduction}

The medical field has its relevance as a tool for decision-making relating to the differential diagnosis, type of treatment required and prognosis. In this perspective, the psychological assessment purposes are to identify the psychological and neurological repercussions caused by the disease or injury process [1]. In opposed to medical tools, one of the central assumptions during this procedure is the use of assessing personality in an unconscious mind. From a psychoanalytic perspective an indirect approach such as projective drawing is an effective instrument that helps in viewing the inner world, unconscious defenses and conscious resistance. Moreover, Projective drawing test is a tool that allows also achieving information concerning the sensitivity and maturity of the patient, as a part of integrated personality and his interpersonal interaction with the environment [2]. In recent decades, a widespread use with projective tests as a tool for psychodiagnostic and neuropsychological assessments has become popular. Today there is no doubt that drawing test is a tool that allows getting information about the vulnerabilities, the maturity of the patient's personality integration and inter-personal interaction with his environment [3].

Goodenough [4] has already reported in the twenties of the last century on many clinical findings that can be produced by children's drawings and deduce the mental states beyond the level of intelligence. The test can also provide a lot of information about cognitive function, since it requires visual-spatial skills, attention and concentration and accurate perception of visual stimuli. HFD test (Human Figure Drawing) is an abbreviated test which was developed several decades later, with the aim to evaluate various psychological states, such as psychosocial status [5]. The practice of using human figure drawings (HFDs) to assess intellectual and psychological ability is pervasive among psychologists and therapists in many countries [6]. Recently a positive relationship was found between the size of the painting and the self-esteem of students in secondary division. Also found a positive correlation between the size of a cartoon character and its details and the degree of self-esteem in men [7].

Historically, DAP test (draw a person) or HFD was developed as a tool that allows assessing the level of intelligence of children. Actually, much earlier [4] reported numerous clinical findings which it is possible to draw beyond the level of intelligence. Consequently, Makower has expanded the use of DAP test tool that allows getting a personal information about the patient [8]. And then, one of the most significant studies were done in the context of a test attests to the reliability of the
DAP / HFD by showing a significant correlation with other drawing tests. Despite the frequent use, there is controversy about the utility test for clinical use [9]. Koppitz [10] has defined an objective signs of emotional indicators that reflect the concerns or fears of the child. This test can also provide neurological information about the cognitive function of the subject such as agnosia and apraxia because they require skills and visual spatial, spatial orientation, attention, concentration and accurate perception of the visual stimulus lenders motor functions [11]. In light of studies that have found differences in elderly demented individuals in HFD test vs. healthy subjects; a study was conducted in an adult population to see if you can raise the validity of the test that examines dementia (MMSE) test using HFD. The subjects were asked to draw a man and a body painting particles were tested in comparison with a list of parts that the absence may predict dementia. They concluded that although test HFD cannot replace the existing tests for dementia, but it contributes to raising sensitivity and integration of the findings [11]. It was well proven that art activities are considered as suitable for creating a context through which a patient can upload your feelings and to express himself [7]. However Goodenough [4] has suggested that artistic qualities per se of the drawing are a negligible factor. However, there may be cognitive variables which now the tendency is to ignore them projective test, particularly the test of HFD.

Cognitive styles are attributed to individual differences in the way people perceive, think, learn and interact with their environment. Witkin [12] by definition, cognitive style affects how information is represented, so the information will be represented in different ways depending on the style of cognitive and this will also affect how information processing and reaction [13]. One of the cognitive style delegates is the verbal and visual axis. Accordingly, when visual individuals are processing information, they are spontaneity experiencing mental sequence of images representing the information, or mental visual information

*Corresponding author: Gigi A, Department of Psychology \& Behavioral Sciences, Ariel University, Israel, Tel: + 972-3-6438352; Fax: + 972-3-9066629 E-mail: Arielag@ariel.ac.il

Received: January 18, 2016; Accepted: January 19, 2016; Published: January 26,2016

Citation: Gigi A (2016) Human Figure Drawing (HFD) Test is affected by Cognitive Style. Clin Exp Psychol 2: 111. doi:10.4172/2471-2701.1000111

Copyright: (c) 2016 Gigi A. This is an open-access article distributed under the terms of the Creative Commons Attribution License, which permits unrestricted use, distribution, and reproduction in any medium, provided the original author and source are credited. 
then arises associatively. By contrast, when verbal individuals read, see or hear something, they process information literally or by verbal associations. For example, verbal people can represent verbal thoughts by writing words on a page, while visual people with sketches. Verbal people are creating images if they try, but it is not a natural situation for them [14]. Accordingly, it is common for example to associate designer as of visual thinking ability, when representations that serve them are not only verbal, but also have a variety of shapes and patterns [15]. Evidence of this assumption was by correlating acceptance tests for Architecture by their cognitive style. Candidates were given the task of designing a week before the interview and were asked to create a model town with a conceptual design. After the interview we examined their cognitive style using a computerized task. Results demonstrated that cognitive style is strong and reliable predictor of success in the admission tests, as well as success in the first year of study design [16]. Additionally, studies found that the distribution between verbal and visual is not dichotomous but axis sequence, and only about $20-30 \%$ of the population has a visual cognitive style, while the majority has a verbal style $[17,18]$.

Based on previous studies relating the linkage between cognitive style and design capabilities $[16,19,20]$ it was assumed, here, that there will be differences in the number of the drawn items in HFD on basis of verbal-visual tendency, and that cognitive style is an intervening variable in HFD test results. Hypothesis was that individuals with visual cognitive style will be presenting more information in HFD test, including organs and accessories and thus will be ranked higher than verbal cognitive style individuals.

\section{Methods}

\section{Subjects}

The study involved a total of 70 healthy subjects (according to personal report) aged 20-30, undergraduate students in the department of Psychology and Behavioral Sciences at University of Ariel. The study was conducted in accordance with departmental ethics committee requirements. All subjects signed a consent form and after execution they were rewarded through a coupon which underlying degree requirements.

\section{Tools}

Test HFD: The participant was provided with a pencil and blank sheet of paper and was told to make the best possible drawing of the whole figure of a man. The test was not timed. To include subject's drawing in the study it must contain of basic organs (body, head, eyes, mouth, nose, legs, and arms). We based on [11] body details list of the human figure drawing. Each item was calculated for the total points beyond the basic items (body, head, eyes, mouth, nose, legs, arms), and each organ / item worth one point.

Visual/Semantic categorization test: Is designed to assess the participant's cognitive style [17] consists of twenty-four stimuli. Each stimulus includes four words items, with two types of exceptions: one item (of the four item words) is exceptional on functionally basis and the other exceptional item is on visually basis. For example, in the cluster, 'WATERMELON; BALL; CARDS; BALLOON', the 'WATERMELON' is exceptional functionally (all the other three are games or toys), and the 'CARDS' is exceptional visually (the other three are characterized by a spherical shape; in Hebrew there is a special word for 'playing cards'). It is important to emphasize that during the explanations that were given to the participants, it did not include information about the existence of the two exceptions. For each participant a functional-semantic/ visual indexing was calculated [16] indicating cognitive-style type and intensity was calculated as well. The index - called the cognitive index - was calculated according to the formula $(\mathrm{S}-\mathrm{V}) /(\mathrm{S}+\mathrm{V})$ : sum of the semantic selections (S) minus sum of visual choices (V), divided by sum of semantic and visual answers together. The index values range from (1) to $(-1)$; a negative result indicates the presence of a visual style, while a positive result points to the dominance of a semantic style. Accordingly, as much as the index is closer to the extreme values of the scale, a clear and significant thinking style is reflected.

\section{Results}

Consistent with previous research, and according to the Visual/ Semantic Categorization Test (VSCT; $[17,18]$, out of seventy individuals only eighteen of them (25.7\%) were with visual cognitive style tendency, and the other 52 individuals were with verbal/semantic cognitive style. Comparing the HFD quantity of items drawn by each cognitive style group revealed a significant difference $(\mathrm{t}(68)=2.0 ; p=0.05)$, when the visual group drew an average of slightly more items $(16.7 \pm 2.4)$ than the verbal cognitive style group $(15.1 \pm 2.7)$.

Examining the relationship between the intensity of cognitive style and amount of detail painted by the participants revealed a significant correlation $(\mathrm{R}=0.25 ; p=0.04)$, so that the as far as a participant has a stronger visual style he/she is drawing more detail when drawing human, and vice versa. As the participant with more verbal cognitive power, so he is drawing fewer details.

\section{Discussion}

Projective analytic theory is based on the assumption that deep and often unconscious feelings and motives may be accessed through various means of self-expression. Drawing tests (HFD and House Tree Person (HTP) tests) are widely used as part of projective tests for assessment of psychological state. The drawing of human figure is widely managed as an ideal instrument for self-expression [21]. The popularity of the test is not questionable due to its easy administration and scoring. Though the interpretation of the test is targeted to psychic aspect of the person, researchers have found the test as effective in assessing neurological intactness, visual-motor coordination [22], cognitive development [23] and learning disabilities. Thus, reliance on the drawings must be proven that it has no bias due to cognitive differences between subjects. In the present study it is demonstrated that drawing tests are influenced, to a certain extent, by the subject's cognitive style. The findings are consistent with previous studies that found an association between cognitive style and visual design capabilities high [15,16], and artistic abilities [24]. The differences obtained in the present study were clear, distinct and significant. It can be argued that, despite the apparent significance, the differences are not large. However, it should note that the test here was very shallow and relied only on the quantity of drawn items. Of course that in order to better understand the contribution of cognitive style it requires to thorough research with not only the quantity but also the quality of details and its projection on emotional conclusions. The results are important through the conceptual level, although of course study is limited by the small subject's number so it is expressed in a relatively small amount of visual subjects.

\section{References}

1. Pinheiro IV, Costa AG, Rodrigues DCB, Oliveira NP, Malheiro AJ, et al. (2015) Hospital psychological assessment with the drawing of the human figure: $A$ contribution to the care to oncologic children and teenagers. Psychology 6: 484-500.

2. Waiswol N (1995) Projective techniques as psychotherapy. American journal 
of psychotherapy.

3. Ramos FS (2007) Imaginary pictures, real life stories: The Foto dialogo method. International Journal of Qualitative Studies in Education 20: 191-224.

4. Goodenough F (1926) Measurement of intelligence by drawing. New York: World Book.

5. Dans-Lopez G, Tarroja MCH (2010) Exploring human figure drawings as an assessment tool for departing OFW domestic helpers and caregivers. Philippine Journal of Counseling Psychology 12: 13-38.

6. Imuta K, Scarf D, Pharo H, Hayne H (2013) Drawing a close to the use of human figure drawings as a projective measure of intelligence. Plos One 8: 58991.

7. Li CY, Chen TJ, Helfrich C, Pan AW (2011) The development of a scoring system for the kinetic house-tree-person drawing test. Hong Kong Journal of Occupational Therapy 21: 72-79.

8. Gustafson JL, Waehler CA (1992) Assessing concrete and abstract thinking with the Draw-a-Person technique. Journal of personality assessment 59: 439447.

9. Glutting JJ, Nester A (1986) Koppitz emotional indicators as predictors of kindergarten children's learning-related behavior. Contemporary educational psychology 11: 117-126.

10. Koppitz EM, Casullo MM (1983) Exploring cultural influences on human figure drawings of yotmg adolescents. Perceptual and Motor Skills 57: 479-483.

11. Wang HX, Ericsson K, Winblad B, Fratiglioni L (1998) The human figure drawing test as a screen for dementia in the elderly: A community-based study. Archives of gerontology and Geriatrics 27: 25-34

12. Witkin HA, Moore CA, Goodenough DR, Cox PW (1977) Field-dependent and field-independent cognitive styles and their educational implications. Review of educational research 47: 1-64.

13. Sadler-Smith E, Riding R (1999) Cognitive style and instructional preferences.
Instructional Science 27: 355-371.

14. Riding RJ, Grimley M, Dahraei H, Banner G (2003) Cognitive style, working memory and learning behaviour and attainment in school subjects. British Journal of Educational Psychology 73: 149-169.

15. Goldschmidt G, Smolkov M (2006) Variances in the impact of visual stimuli on design problem solving performance. Design Studies 27: 549-569.

16. Casakin H, Gigi A (2016) Cognitive styles in admission procedures for assessing candidates of architecture. Assessment and Evaluation in Higher Education 41: 167-182.

17. Gigi A (2006) Do people with varying cognitive style access semantic knowledge differently? annual conference of the cognitive science society. Cognitive Conference.

18. Gigi A (in press) Thinking the literal by images: Styles differences in approach to semantic information.

19. Kim MH, Kim YS, Lee HS, Park JA (2007) An underlying cognitive aspect of design creativity: Limited Commitment Mode control strategy. Design Studies 28: $585-604$

20. Kozhevnikov M, Kozhevnikov M, Yu CJ, Blazhenkova O (2013) Creativity, visualization abilities, and visual cognitive style. British Journal of Educational Psychology 83: 196-209.

21. Khan NA, Kanchan A, Jahan M, Amool R, Singh S (2011) Human figure drawings of normal Indian adults. SIS J Proj Psy \& Ment Health 18: 50-61.

22. Holmes CB, Stephen CL (1984) Consistency of edging on the Bender-Gestalt, Memory for Designs, and Draw-a-Person tests. The Journal of Psychology 117: 269-271.

23. Abell SC, Heiberger AM, Johnson JE (1994) Cognitive evaluation of young adult by means of human figure drawings: An empirical investigation of two methods. Journal of clinical psychology 50: 900-905.

24. Kozbelt A (2001) Artists as experts in visual cognition. Visual Cognition 8: 705 723 